\title{
BP Neural Network-Based Risk Assessment for Industrialization of Patent Technology
}

\author{
Dongdong $L u^{1, a}$
}

\author{
Beijing Jiaotong University,No.3 Shangyuancun,Haidian District, Beijing,P. R. China 100044 \\ Email:lu101105@163.com
}

Keywords: Industrialization; Patent technology; Risk identification; Risk assessment; BPNN

\begin{abstract}
Industrialization process of patent technology is one of the most important marks to evaluate patent technology innovation ability, which affects their own survival and development in the competition. But the ratio of industrialization is still very low, because there are some restricted risks through the industrialization process. So, if a reasonable risk assessment system for industrialization of patent technology could been put forward based on the analyst for the risks, and some suitable theory could been applied for the assessment, it would do great contribution, offer objective database and implementation guidance to the industrialization of patent technology .Aim at risk assessment for industrialization of patent technology, the paper puts forward the construction of the patent industrialization index system based on the analyst for the risks. And BPNN theory could be applied for the assessment. As a case study, A University has been chosen for an example to prove the correctness of the conclusion and effectiveness of the assessment.
\end{abstract}

\section{Introduction}

China has made remarkable achievements in economic development, but compared with developed countries, there is still a considerable gap with industrialization of patent technology. We should give enough attention to it. After some basic theory research for the industrialization of patent technology and risk assessment [1,2,3]. We will make the risk assessment for industrialization of patent technology more scientific and objective[4,5]. this paper puts forward the risk evaluation index system for industrialization of patent technology . And based on the principle of BP neural network, BPNN risk assessment model is established for industrialization of patent technology[6].

\section{The establishment of risk assessment index system for industrialization of patent technology}

To carry out the risk assessment of industrialization of patent technology, the most important step is to establish a scientific, objective and impartial evaluation index system. This paper widely consults the foreign and domestic literature, and focuses on the risk assessment of the indicators that have been widely used in many literature index. This paper will give particular attention to these. Based on the principle of industrialization of patent technology, the author establishes the risk assessment index system for industrialization of patent technology[7 8] As is shown in table 1. 
Table 1 The risk assessment index system

\begin{tabular}{|c|c|c|}
\hline & Index class one & Index class two \\
\hline & & The policy orientation $\mathrm{A}_{11}$ \\
\hline & & The efficiency of the system and execution $\mathrm{A}_{12}$ \\
\hline & The University's & Scientific researchers' personnel quality $\mathrm{A}_{13}$ \\
\hline & own risk $\quad A_{1}$ & University research funds $\mathrm{A}_{14}$ \\
\hline & & The quality of patent managers $A_{15}$ \\
\hline & & Rationality of interest distribution system $\mathrm{A}_{16}$ \\
\hline assessment & The risk of & The maturity of patent technology $\mathrm{A}_{21}$ \\
\hline index & industrialization & The fusion of patent technology $\mathrm{A}_{22}$ \\
\hline system & for patent & The development of patent technology $\mathrm{A}_{23}$ \\
\hline & Technology $\mathrm{A}_{2}$ & The hierarchy of industrialization $\mathrm{A}_{24}$ \\
\hline industrialization & & The diversity of industrialization $\mathrm{A}_{25}$ \\
\hline of & $\begin{array}{l}\text { The risk of } \\
\text { The parties }\end{array}$ & $\begin{array}{l}\text { The cooperation between enterprise and } \\
\text { University } A_{31}\end{array}$ \\
\hline technology & involved in the & Awareness of the enterprise market $\mathrm{A}_{32}$ \\
\hline & patent & The innovation ability of enterprises $\mathrm{A}_{33}$ \\
\hline & technology $\mathrm{A}_{3}$ & The legal policy $\mathrm{A}_{34}$ \\
\hline & & Enterprise research funding $\mathrm{A}_{35}$ \\
\hline & The risk of & Market evaluation system $\mathrm{A}_{41}$ \\
\hline & external & Market trading platform $\mathrm{A}_{42}$ \\
\hline & environment $\mathrm{A}_{4}$ & The development and perfection of policy $\mathrm{A}_{43}$ \\
\hline & & The convenience of research funding $\mathrm{A}_{44}$ \\
\hline
\end{tabular}

\section{BP Neural Network}

BP neural network is a multilayer feedforward neural network trained by back-propagation algorithm. It's named for it uses BP learning algorithm. Under the condition that its input and output in the system are unknown and through a large number of mapping relation of input and output in training system of internal storage and internal mechanism, we can extract the implication of the system[9].

The BP neural network model including node output model, function model ,error calculation model and the self-learning model[9].

(1) Node output model

The hidden nodes and output model: $\mathrm{O}_{\mathrm{j}}=\mathrm{f}\left(\Sigma \mathrm{W}_{\mathrm{ij}} \times \mathrm{X}_{\mathrm{i}}-\theta_{\mathrm{j}}\right)$

Output node output model: $\mathrm{Y}_{\mathrm{k}}=\mathrm{f}\left(\Sigma \mathrm{T}_{\mathrm{jk}} \times \mathrm{O}_{\mathrm{j}}-\theta_{\mathrm{k}}\right)$

(2) Function model

General admission for $(0,1)$ in the continuous value for Sigmoid function:

$$
\mathrm{F}(\mathrm{x})=1 /\left(1+\mathrm{e}^{-\mathrm{x}}\right)
$$

(3)Error calculation model

$$
\mathrm{E}_{\mathrm{p}}=1 / 2 \times \Sigma\left(\mathrm{t}_{\mathrm{pi}}-\mathrm{O}_{\mathrm{pi}}\right)^{2}
$$

(4) Self-learning model

$$
\Delta \mathrm{W}_{\mathrm{ij}}(\mathrm{n}+1)=\eta \times \Phi_{\mathrm{i}} \times \mathrm{O}_{\mathrm{j}}+\mathrm{a} \times \Delta \mathrm{W}_{\mathrm{ij}}(\mathrm{n})
$$

f: non-linear function; $\quad \theta$ :threshold neural unit;

tpi: The expected output value of the node; $\quad \mathrm{O}_{\mathrm{pi}}$ : The output value of node calculation; $\eta$ : learning factor; $\quad \Phi_{i}$ : the calculation error of the output node $\mathrm{i}$;

$\mathrm{O}_{\mathrm{j}}$ : calculate the output node $\mathrm{j} ; \quad \mathrm{a}$ : momentum factor. 


\section{The establishment of the sample system}

In this paper, based on the investigation of A University, we sort out the basic data for the risk assessment for industrialization of patent technology, in which some qualitative data uses expert scoring method. But because of the existence of the dimensionless unit, the difference between the index data and both qualitative indexes and quantitative indicators, in order to facilitate the commensurability and optimization analysis, the differences between the dimensions of the unit project evaluation are normalized before dealing with the evaluation index. Specifically, the patent technology evaluation index is generally divided into two kinds, the positive index (the bigger the better) and reverse index (the smaller the better), they must be quantified for the closed interval $[0,1]$.

For positive index: $\mathrm{F}_{\mathrm{j}}=1-\left(\mathrm{X}_{\mathrm{j}}-\mathrm{X}_{\mathrm{jmin}}\right) /\left(\mathrm{X}_{\mathrm{jmax}}-\mathrm{X}_{\mathrm{jmin}}\right)$

For reverse index: $\mathrm{Fj}=\left(\mathrm{X}_{\mathrm{j}}-\mathrm{X}_{\mathrm{jmin}}\right) /\left(\mathrm{X}_{\mathrm{jmax}}-\mathrm{X}_{\mathrm{jmin}}\right)$

Among them, $F_{j}$ is the coefficient for the target value $X_{j}, X_{j m i n}$ is determined as the minimum value of each index for $\mathrm{J}$ in advance; $\mathrm{X}_{\mathrm{jmax}}$ is determined as the maximum value of each index for the $\mathrm{j}$ in advance, $\mathrm{J}$ is the number of evaluation index. After the process, we can get the sample data. As is shown in table 2.

Table 2 sample data quantization table

\begin{tabular}{|c|c|c|c|c|c|c|c|c|c|c|c|c|c|c|c|}
\hline N.O & \multicolumn{15}{|c|}{ sample } \\
\hline Index & 1 & 2 & 3 & 4 & 5 & 6 & 7 & 8 & 9 & 10 & 11 & 12 & 13 & 14 & 15 \\
\hline A11 & 0.534 & 0.477 & 0.845 & 1.000 & 0.364 & 0.756 & 0.457 & 0.562 & 0.357 & 0.347 & 0.277 & 0.875 & 0.247 & 0.329 & 0.588 \\
\hline A12 & .000 & 0.000 & 0.000 & 1.000 & 0.750 & 0.500 & 0.250 & 0.750 & 0.500 & 1.000 & 0.750 & 1.000 & 0.250 & 0.250 & 1.000 \\
\hline A13 & .571 & 0.463 & 0.328 & 0.853 & 0.265 & 1.000 & 0.356 & 1.000 & 0.153 & 0.328 & 0.488 & 0.871 & 0.299 & 0.655 & 0.755 \\
\hline A14 & 0.246 & 0.568 & 0.465 & 0.893 & 0.747 & 0.682 & 0.326 & 0.478 & 0.682 & 0.248 & 0.000 & 0.653 & 0.325 & 0.265 & 0.235 \\
\hline A15 & 0.659 & 0.939 & 0.700 & 0.736 & 0.781 & 0.708 & 0.431 & 1.000 & 0.413 & 0.221 & 0.223 & 0.234 & 0.000 & 0.227 & 0.462 \\
\hline A16 & 0.000 & 0.969 & 0.940 & 0.967 & 0.846 & 0.925 & 0.654 & 0.991 & 0.983 & 0.346 & 0.991 & 0.983 & 1.000 & 0.994 & 0.913 \\
\hline A21 & 0.587 & 0.536 & 0.359 & 0.527 & 1.000 & 0.411 & 0.761 & 0.324 & 0.308 & 0.052 & 0.047 & 0.000 & 0.193 & 0.257 & 0.123 \\
\hline A22 & 0.334 & 0.563 & 0.872 & 0.257 & 0.984 & 0.246 & 0.668 & 0.000 & 0.986 & 0.256 & 0.872 & 1.000 & 0.325 & 0.213 & 0.842 \\
\hline A23 & 0.365 & 0.446 & 0256 & & 0.789 & 0.326 & 0.546 & 0.343 & 0.781 & 0.000 & 0.658 & 0.118 & 0.659 & 1.000 & 0.345 \\
\hline A24 & 0.686 & 0.959 & 0,70 & 0.753 & 0,781 & 0,785 & 0,703 & 0.430 & 1.000 & 0.356 & 0.457 & 0.000 & 0.071 & 0.327 & 0.492 \\
\hline A25 & 0.970 & 1.000 & 0.953 & 0.965 & 0.967 & 0.812 & 0.963 & 0.972 & 0.957 & 0.945 & 0.000 & 0.848 & 0.327 & 0.687 & 0.503 \\
\hline A31 & 0.247 & 0.000 & 0.235 & 0.213 & 0.000 & 0.248 & 0.578 & 0.366 & 0.467 & 0.789 & 0.367 & 0.461 & 0.756 & 0.965 & 1.000 \\
\hline A 32 & 0.389 & 0.697 & 0.645 & 0.235 & 0.456 & 0986 & 0.324 & 0.000 & 0.674 & 0.268 & 0.782 & 0.267 & 1.000 & 0.683 & 0.587 \\
\hline A33 & 0.658 & 0.236 & 0.456 & 0.908 & 0.782 & 0.093 & 0.938 & 0.411 & 0.000 & 0.413 & 0.338 & 0.854 & 1.000 & 0,856 & 0.604 \\
\hline A34 & 1.000 & 0.500 & 0.500 & 1.000 & 0.000 & 0.500 & 0.000 & 1.000 & 0.500 & 0.500 & 1.000 & 1.00 & 0.000 & 0.500 & 1.000 \\
\hline A 35 & 0.876 & 0.658 & 0.463 & 0.09 & 0.164 & 0.000 & 0.325 & 0.755 & 0.627 & 0.461 & 0.746 & 0.267 & 0.367 & 0.783 & 0.691 \\
\hline A41 & 0.250 & 0.750 & 0.500 & 0.000 & 0.000 & 0.500 & 0.750 & 0.500 & 0.250 & 0.250 & 0.250 & 0.250 & 0.750 & 0.000 & 1.000 \\
\hline A42 & 0.634 & 0.47 & 0.734 & 0.267 & 0.563 & 0.357 & 0.126 & 0.892 & 0.468 & 0.658 & 0.361 & 0.462 & 1.000 & 0.652 & 0.267 \\
\hline A43 & 1.000 & 1.000 & 0.500 & 0.000 & 1.000 & 1.000 & 0.500 & 0.000 & 1.000 & 1.000 & 1.000 & 0.500 & 0.500 & 0.500 & 0.500 \\
\hline A44 & 0.874 & 0.669 & 0.465 & 0.095 & 0.157 & 0.000 & 0.356 & 0.756 & 0.672 & 0.463 & 0.268 & 0.000 & 0.325 & 0.745 & 0.981 \\
\hline Actual & 0.641 & 0.602 & 0.733 & 0.698 & 0.687 & 0.572 & 0.736 & 0.393 & 0.724 & 0.413 & 0.292 & 0.642 & 0.508 & 0.678 & 0.781 \\
\hline
\end{tabular}




\section{The establishment and the simulation training of BP neural network}

The establishment of BP neural network. The value of the output node value depends on risk assessment index to reflect the industrialization of patent technology . In this paper, the value for risk assessment is from 0 , up to 1 , which is divided into 3 grades. As shown in table 3:

Table 3 Coefficient table of risk assessment

\begin{tabular}{|c|c|}
\hline Level of risk assessment & Grade coefficient of risk assessment \\
\hline High & $0.6-1$ \\
\hline Gneral & $0.4-0.6$ \\
\hline Low & $0-0.4$ \\
\hline
\end{tabular}

Among 15 samples, the samples 1-10 are as the training sample, the sample 11-15 are as test samples to verify the effect of network training.

(1) Determination of network layer

Any continuous function on a closed interval can be approached when using BP neural network with one hidden layer, and a 3 layer BP neural network can perform any $\mathrm{N}$ to $\mathrm{M}$ dimensions of the map. So the single hidden layer network is widely used in the BP neural network.

(2) Determination of the network input layer nodes i

The number of input nodes is corresponding with the number of the evaluation index. In this paper, we use 20 indicators of risk assessment, so $\mathrm{i}$ is set to 20 .

(3) Determination of the hidden layer nodes $\mathrm{j}$

The nonlinear mapping ability of single hidden layer network is weak .For the same problem, in order to achieve the mapping relationship preset, hidden layer nodes should be added so that the network can adjust the parameters. And ultimately we determine the number of hidden layer is 20.

(4) Determine of the output layer nodes $\mathrm{k}$

As the network output is only one indicator -- the grade coefficient of risk assessment, so the number of nodes $\mathrm{k}$ is 1 .

BP neural network simulation training. Before the network training, we must initialize network weights and threshold. Newff in the establishment of the network will initialize the network weights and threshold directly. Because the input data is on $[0,1]$, hidden layer may choose Logsig conversion function and the output layer use Purelin conversion function. And we use the gradient descent method with momentum (traingdm) with training network[10]. The results of the risk assessment of network training and actual results are shown in table 4.Evaluation of 5 test simulation results and actual results are shown in table 5. From tables 4 and 5 we can be see, not only all the training samples and the actual assessed value is very close, but also the 5 test simulation results and the actual assessed value is very close. The largest error is less than $1 \%$.

Table 4 The comparison results between network training and the actual

\begin{tabular}{|c|c|c|c|c|c|c|c|c|c|c|}
\hline N.O & 1 & 2 & 3 & 4 & 5 & 6 & 7 & 8 & 9 & 10 \\
\hline Actual & 0.641 & 0.602 & 0.733 & 0.698 & 0.687 & 0.572 & 0.736 & 0.393 & 0.724 & 0.413 \\
\hline Network training & 0.643 & 0.601 & 0.730 & 0.694 & 0.681 & 0.577 & 0.736 & 0.395 & 0.723 & 0.411 \\
\hline Error & $0.47 \%$ & $0.17 \%$ & $0.41 \%$ & $0.57 \%$ & $0.87 \%$ & $0.87 \%$ & $0.00 \%$ & $0.05 \%$ & $0.01 \%$ & $0.48 \%$ \\
\hline
\end{tabular}


Table 5 Comparison of the simulation results and the actual

\begin{tabular}{|c|c|c|c|c|c|}
\hline N.O & 11 & 12 & 13 & 14 & 15 \\
\hline Actual & 0.292 & 0.642 & 0.508 & 0.678 & 0.781 \\
\hline simulation results & 0.294 & 0.641 & 0.504 & 0.672 & 0.780 \\
\hline Error & $0.68 \%$ & $0.16 \%$ & $0.78 \%$ & $0.88 \%$ & $0.13 \%$ \\
\hline
\end{tabular}

\section{Conclusion}

(1) There are many factors affecting the patent technology industrialization, and it's very complicated. All above results in the fact that risk assessment has become a difficult task. In this paper, BP neural network method for risk assessment of industrialization of patent technology can consider a large amount of influencing factors, which can be either qualitative or quantitative factors. It's simple, accurate and advanced.

(2)The learning samples are derived from real data results, which avoid the subjective factors. What's more, further improvement of learning samples can increase the accuracy of assessment result, so it has wide applicability.

(3) BP neural network model is feasible for risk assessment for industrialization of patent technology. BP neural network can be accurately and practical, which is significant to improve the efficiency and to reduce the risk of the industrialization of patent technology.

\section{Literature References}

[1]Norman Doelling. Technology Transfer among Government, Industry and Academia: Experience at the MIT Sea Grant College Program [J].IEEE.2000

[2]Elfenbein DW.Publications, patents and the market for university inventions. Journal of Economic Behavi or \& Organization . 2007

[3]Jinliang Tao,Qibin Zhao. Patent technology transfer [M].Beijing: Intellectual property press.2011

[4]Yanqiong Liu,Yongping Shen. Risk assessment of research method and theoretical review. http://www.cnki.net

[5] Lixin Liu.Risk Management[M].Beijing:Peking University Press,2011.

[6]Minli Yang,Bo Zha. GA-BP neural network based process evaluation of patent technology [J]. Science \& Technology Progress and Policy.2010(10):117-120

[7]Hong Zhou. Comprehensive evaluation of scientific and technological achievements based on BP neural network [J] Decision and reference.2009(17):79-81

[8]Baolian Tang, Wei Pan. The evaluation index system research for patent industrialization[ J] . Journal of Information, 2003(1) .

[9]Feng Quan,Changwei Liu. Analysis of factors influencing college patent technology transformation and implementation [J]. Agricultural science and technology management.2007(08):59-63

[10] Guoyong Li. Intelligent control and its MATLAB implementation [M]. Electronic Industry Press.2005 